\title{
Perífrasis verbales en conexión con textos narrativos y expositivos escritos por niños cartageneros $y$ bogotanos
}

\author{
Clara Inés Fonseca Mendoza ${ }^{1}$ \\ Universidad de Cartagena
}

\section{Resumen}

Este artículo aborda el tema de los rasgos lingüísticos que distinguen textos narrativos y expositivos. En particular se estudia en ellos la co-ocurrencia de algunas perífrasis verbales y su temporalidad. Los datos en que se basa el análisis proceden de 40 muestras escritas por niños cartageneros y bogotanos. El objetivo es realizar una descripción de los valores aportados por las perífrasis: tener que + infinitivo; ir $\mathrm{a}+$ infinitivo, $y$ algunas de gerundio, observando que dichos valores son diferentes de acuerdo al tipo de texto y a la región de procedencia del hablante.

Palabras clave: relaciones gramática-discurso, perífrasis verbales, textos narrativos, textos expositivos.

\section{Abstract}

This article approaches the subject of the linguistic features that distinguish narrative and expositive texts; particularly, the Cooccurrence of some verbal periphrasis and their temporality in them are studied. The data, on which the analysis is based, come from 40 samples written by Children from Cartagena and Bogotá. The aim is to make a description of the values given by the periphrasis: to have to + infinitive (tener que + infnitivo); to be going to + infinitive (ir a + infinitivo) and some of gerund, being observed that these values are different according to the text type and the speaker's region of Origen.

Key words: grammar-speech relations, verbal periphrasis, narrative texts, expositive texts.

\footnotetext{
${ }^{1}$ Licenciada en Filología e Idiomas de la Universidad Nacional de Colombia. Magister en Lingüistica de la Universidad Nacional de Colombia. Docente de tiempo completo del Programa de Linguística y Literatura de la Universidad de Cartagena. El presente documento hace parte del trabajo Formas verbales y temporalidad en conexión con la estructura de textos narrativos y expositivos escritos por niños cartageneros y bogotanos (2006), llevado a cabo en la línea de investigación "Comprensión y producción de textos” del Grupo de Investigación Texcultura. E-mail: texcultura@ hotmail.com.
} 


\section{Los textos narrativos y los expositivos como formas de expresión del pensamiento}

Bruner (1994) propone dos maneras de ordenar la experiencia para la construcción del sentido de lo real, es decir, dos formas de pensamiento convergentes. Son ellas las modalidades paradigmática y narrativa:

Una de las modalidades, la paradigmática o lógico-científica, trata de cumplir el ideal de un sistema matemático, formal, de descripción y explicación. Emplea la categorización o conceptualización y las operaciones por las cuales las categorías se establecen, se representan, se idealizan y se relacionan entre sí a fin de constituir un sistema. [...]. Su lenguaje está regulado por requisitos de coherencia y no contradicción. Su ámbito está definido no sólo por entidades observables a las cuales se refieren sus enunciados básicos, sino también por la serie de mundos posibles que pueden generarse lógicamente y verificarse frente a las entidades observables; es decir, está dirigida por hipótesis de principios [...]. La aplicación imaginativa de la modalidad paradigmática da como resultado una teoría sólida, un análisis preciso, una prueba lógica, argumentaciones firmes y descubrimientos empíricos guiados por una hipótesis razonada [...]. La aplicación imaginativa de la modalidad narrativa produce, en cambio, buenos relatos, obras dramáticas interesantes, crónicas históricas creíbles (aunque no necesariamente "verdaderas"). Se ocupa de las intenciones y de las vicisitudes y consecuencias que marcan su transcurso (24-25).

Se deduce que el denominado modo paradigmático es característico de ciencias como la matemática, la física y las ciencias naturales. La otra modalidad es propia de la ficción. Estas formas de proceder del pensamiento, paradigmática y narrativa, pueden expresarse en modelos textuales diferentes: en textos expositivos, informativos o argumentativos la primera, y en diversas formas de textos narrativos la segunda.

\section{Características de los textos narrativos y expositivos}

En términos generales cualquier cosa puede narrarse o informarse. Como lo señala van Dijk (1983), un hecho como un robo, por ejemplo, bien puede ser narrado por quien fue asaltado, informarse en 
un noticiero o denunciarse en una comisaría, entre otros. En cada ocasión el tratamiento de ese mismo tema tendrá una construcción textual diferente puesto que diferente es la función comunicativa.

Ahora bien, lo que se narra, a diferencia de lo que se informa, es generalmente un hecho inusual, no cotidiano: "If the event is reportable, it does not happen every day, as a product of every day activities" (Labov, 2006: 2). Si se quiere narrar algo, hacer extraño lo ordinario (Bruner, 1991), o "explicar el suceso o las acciones que hasta cierto punto se desvían de una norma, de expectativas o de costumbres" (van Dijk, 1983:154), se debe dar un paso previo o, en otras palabras, un paso atrás en el tiempo y describir lo que sucedía antes de que ocurriese el evento que merece contarse, es decir, lo que era usual o cotidiano; es este el inicio en los textos narrativos (Labov, 2006). Luego, sí cabe la pregunta: “¿Y qué pasó?"2, dando lugar al primer evento de la narrativa. Esto no ocurre cuando se informa sobre estados de cosas o sobre localización de entidades: quien informa no responde necesariamente a la pregunta: “Qué sucedió?”; por ello no reporta en pasado, o lo hace sólo si debe ejemplificar, o cuando discute secuencias o procesos (Callaway y Lester, 2001).

Por otra parte, las formas del discurso como la narración y la exposición pueden diferenciarse por el empleo de "transformaciones subjuntivizadoras": "usos léxicos y gramaticales que realzan estados subjetivos, circunstancias atenuantes y posibilidades alternativas" (Bruner, 1991: 55). Así, las narrativas tienden a ser más subjetivas y específicas. Los textos expositivos, por su parte, son metatextuales, de actitud cognitiva o epistémica y de referencia general (Ragnarsdóttir, et. al., 2002).

Berman y sus colaboradores (2002) acogen en tres categorías los rasgos de la construcción textual: orientación, actitud y generalidad. La orientación concierne a la relación entre los tres participantes en la producción/comprensión textual: el emisor (hablante/escritor), el texto (narrativo/expositivo) y el receptor (oyente/lector). Usualmente cuando un texto se orienta hacia el emisor (por ejemplo, "yo creo..."), el producto es subjetivo, centrado deícticamente. La orientación hacia el receptor (i.e., "como ustedes saben") implica motivaciones comunicativas. La orientación hacia el texto (i.e., "al considerar este tópico") toma el objeto de comunicación como punto de

\footnotetext{
2 "[...] podemos ver la narrativa como una serie de respuestas a preguntas subyacentes: síntesis: “de qué trata?” Orientación: “¿quién, cuándo, qué, dónde?” Complicación: “entonces ¿qué pasó?” Evaluación: “iy qué?” Resultado “¿qué pasó finalmente?" (Labov, 1988: 23).
} 
referencia conceptual. Por su parte, la actitud puede ser epistémica, deóntica o afectiva. La primera enfatiza la posibilidad, la certeza o la evidencia de lo que se comunica. La segunda, adopta una actitud prescriptiva o evaluativa. La tercera, hacer ver las emociones del emisor. Por último, la generalidad tiene que ver con los grados de referencia: universal, específica o impersonal.

\title{
Perífrasis verbales
}

Gómez Torrego (1988) caracteriza las perífrasis verbales del siguiente modo:

\begin{abstract}
[...] una perífrasis verbal está formada por, al menos, dos verbos morfológicos que constituyen sintácticamente un sólo núcleo verbal [...]. El primero de los verbos es un simple auxiliar, es decir, queda inhabilitado para llevar y seleccionar sujetos o complementos propios [...]. El segundo verbo debe aparecer en infinitivo, gerundio o participio, y poseer pleno carácter verbal sin los valores respectivos de nombre, adverbio y adjetivo, que son inherentes a tales formas no personales (18).
\end{abstract}

En una línea muy parecida a la de Gómez Torrego, Olbertz (2001) define las perífrasis verbales como "[...] la combinación productiva e indivisible de un verbo léxico gramaticalizado con el infinitivo (con o sin preposición), gerundio o participio de un predicado verbal. [...] es una construcción auxiliar cuyo auxiliar se emplea como verbo léxico fuera de la perífrasis" (432). Es debido a ese criterio de productividad que el inventario de posibles perífrasis en español de Olbertz es más restringido que, por ejemplo, el de Gómez Torrego. Por su parte, Fogsgaard (2002) recalca el valor de las perífrasis verbales como instrumentos de manifestación de intenciones comunicativas y expresivas no siempre permitidas por las formulaciones tradicionales correspondientes:

En la perífrasis [...] entran dos formas verbales que se reparten las funciones. El verbo perifrástico (V1), normalmente conjugado, establece el anclaje de la oración, es decir, que tiene la función de amarrar el enunciado refiriéndolo al momento de la enunciación, mientras que la forma no finita, no personal (V2), constituye el núcleo semántico referencial. Ambos forman un conjunto de predicación en una relación de solidaridad. (3) 
Como se observa, la definición de Fogsgaard atiende más a criterios pragmáticos. De hecho, para la autora, es función de los verbos perifrásticos relacionar el escenario al que se refiere el lexema infinitivo con la intención comunicativa del hablante.

\section{Metodología}

El trabajo que a continuación presentamos se llevó a cabo sobre 40 muestras $^{3}$ de textos narrativos y expositivos escritos por niños de quinto grado de dos colegios públicos de la ciudad de Cartagena y uno de la ciudad de Bogotá4. Para obtenerlas se ofreció a los estudiantes una secuencia de tres cuadros: el primero muestra un pájaro trayendo alimento a sus crías (una de ellas parece estar enferma o muerta). En el segundo, el pájaro retira del nido a la cría muerta o enferma. En el tercero, ésta yace al pie de un árbol ${ }^{5}$. El tema de esta secuencia fue discutido con los estudiantes previamente ya que nuestro interés era registrar el modo como un mismo evento es reportado en dos tipos diferentes de texto no sin antes preguntarles las razones por las que se puede encontrar un pichón muerto junto a un árbol. Ninguno de los niños dijo que era porque los padres lo habían sacado por enfermedad o muerte. Daban razones como que se había caído por causa de la lluvia o porque le tiraron piedras. Dos o tres niños dijeron que sus padres lo sacaron porque iban a "hacer" otros pajaritos. Luego, en hojas distintas, se solicitó a un grupo de estudiantes que explicara lo observado en las imágenes y a otro que escribiera un cuento a propósito de las mismas.

La prueba se aplicó en el año 2005, a finales del mes de octubre, en Bogotá, y a comienzos de noviembre, en Cartagena, cuando los niños terminaban el quinto grado escolar. Se les pidió que anotaran la edad y el sexo como variables que pudieran incidir en la producción de los textos ${ }^{6}$. Se obtuvieron 40 textos narrativos, 20 en Bogotá y 20 en Cartagena, y 40 expositivos, igualmente 20 en cada una de las ciudades. De todos ellos se seleccionaron diez muestras de cada tipo de

\footnotetext{
${ }^{3}$ Estas muestras fueron tomadas para una investigación sobre categorías de los textos narrativos y expositivos y sus relaciones con las formas verbales y la temporalidad.

${ }^{4}$ Agradecemos la colaboración de los docentes y directivos de los colegios Integrado de Fontibón, en Bogotá, y Olga González Arraut y Jhon F. Kennedy, en Cartagena.

${ }^{5}$ Este tema aparece en la lectura denominada "Una ley de la naturaleza”, en Jurgen (1981).

${ }^{6}$ En el documento que aquí se presenta no se hacen relaciones con la edad ni el sexo.
} 
texto en cada ciudad, es decir, en total se analizaron 40 muestras ${ }^{7}$. A continuación algunos de los textos producidos ${ }^{8}$.

Texto narrativo. Cartagena:

En una bella mañana los pajaros cantaban y las abes alsaban el buelo las palomas alimentaba asu cria alpasar de os dias de los dias la madre noto que algo andaba mal era que su ijo menor estaba enfermo sufria de una enfermeda mui contagiosa pero ella no lo sabia por lo tanto no lo saco del nido al pasar el tiempo se dio cuenta que empeoraba con mucho dolor lo tubo que sacar del nido al pasar el tiempo otro mas vinieron asubida pero laerida que dejo su ultimo hijo ningun otro la puede curar.

Texto narrativo. Bogotá:

Habia una vez unos pagaritos que sus padres que querian proteger de todo y de todas las personas hasta que uno por equibocación se enfermo porque una persona le prendio una enfermedad y el padre y la madre, todos preocupados fueron bolando a abisarle a el doctor buo sus padres querian salbarlo porque sino lo iban a botar del nido.

Al otro dia el pobre pagarito murio sus padres trataron de salbarlos pero era inútil ya estaba muerto ellos sin mas remedio lo botaron del nido. los padres de los otros paritos no los mataron ni los botaron y fueron entre los cuatro los amaron y fueron felices.

Texto expositivo. Cartagena:

La madre estaba fuera del nido y cuando llega ve a uno de los pichones muerto de imediato la madre coge su pichon arogandolo al suel para evitar contagiar a los demas pichones.

Esto para la madre es normal y seda después de cada parto por medio de su madre.

\footnotetext{
${ }^{7}$ La mayor parte de muestras no analizadas tenían características similares a las escogidas.

${ }^{8}$ Transcribimos las muestras tal y como fueron escritas por los niños. 
Texto expositivo. Bogotá:

Cuando el ave tiene sus crias y una se enferma por alguna razon o motivo sus padres tienen que sacarla del nido, pues si la dejan tendran esa enfermedad asi que la ave se muere porque no tiene protección de sus padres y la ayuda para sobrevivir.

\section{Resultados}

Veamos algunas características generales de los textos producidos por los niños antes de abordar el uso de las perífrasis verbales. Como ya se señaló, un mismo tema puede narrarse o informarse. Así, los niños participantes en este estudio respondieron adecuadamente a la instrucción solicitada: unos describieron la situación y produjeron textos expositivos; otros hicieron una especie de doble ejercicio imaginativo. El hecho real fue singularizado y produjeron textos narrativos. El resultado, entonces, fueron textos que, aunque versan sobre el mismo tema, cumplen funciones sociales diferentes y poseen estructuras diferentes.

Lo narrado, a diferencia de lo explicado o informado, fue reducido a una experiencia individual e inesperada: "la mamá se descuidó y el pájaro se descuidó"; "se cayó y se mató"; "al otro día el pobre pajarito murió"; "ellos sin más remedio lo botaron del nido". Pero para que eventos como estos fueran narrables, es decir, no fueran reportes de productos de actividades cotidianas, los niños imaginaron una situación previa en donde las cosas transcurrían con normalidad: "había una vez una familia feliz [...]”, "los pájaros cantaban, las aves alzaban el vuelo [...]". A la descripción de hechos como éstos cabe la pregunta: ¿y qué pasó? Responder a esta pregunta implica encadenar una sucesión particular de acontecimientos cuya lógica le es dada, más que por la referencia, por el sentido ${ }^{9}$. La narración se convierte en una cadena singular de acontecimientos, los cuales significan no exactamente por la semántica de sus elementos, sino por el texto en que son ordenados (Bruner, 1991).

\footnotetext{
9 "El sentido, o relación del significante con el significado, es distinto de la referencia, o relación del significado con el referente. Para utilizar el ejemplo de Frege, 'el lucero de la tarde' y 'el lucero del alba' tienen el mismo referente (Venus) pero no el mismo sentido (...) el referente no es el mundo tal como es en sí mismo, sino el mundo tal como lo percibe una cultura dada" (Reboul, 1981: 57-58).
} 
En contraste, los textos expositivos, al reportar un evento de carácter general, "obligó" a los niños a usar preferentemente verbos que denotan una situación dinámica, sin duración (Marín, 2000), y a usar verbos de estado: "está muerto/enfermo"; "hay una cría enferma", y verbos que señalan cambios de estado: "se enferma". Cabe señalar que tal vez debido al tema planteado tanto los narrativos como los expositivos organizaron el contenido mediante el modelo problema-solución: un pajarillo enfermo o muerto (complicación/problema) es arrojado del nido (resolución/solución), pero el orden de los eventos fue distinto. En los textos narrativos todos los niños plantearon, en primer lugar, la enfermedad o muerte (como complicación) y luego la expulsión del nido (como resolución). En los expositivos varios niños marcaron primero la solución y después el problema, puesto que el orden en que aparecen los eventos no incide necesariamente en la interpretación del texto ${ }^{10}$.

En cuanto al uso de perífrasis verbales, se obtuvieron, en los textos narrativos, diecinueve en Bogotá y diecisiete en Cartagena; en los expositivos, veintidos en Bogotá y nueve en Cartagena. Algunos de los valores -modal, aspectual y temporal- que estas construcciones aportan a los textos, permiten diferenciarlos, como lo veremos a continuación.

\section{Tener que + infinitivo: valor modal de imposición}

Como lo señala Gómez Torrego (1988), las perífrasis de "tener que + infinitivo" pueden aportar significados de obligación o necesidad ineludible, probabilidad y modalidad intencional o desiderativa: "Sólo aspectos pragmáticos (relativos al contexto) o fónicos (entonación) puede ayudarnos a saber cuál es el significado que predomina" (Gómez Torrego, 1999: 3352). En los textos de los niños el contexto en donde aparecen las mencionadas formas indica valor de necesidad/ obligación. Veamos algunas:

[1] tubieron que tirarlo al piso porque después contagiaba a los otros pichones $\left[\mathrm{NC}^{11}\right]$

\footnotetext{
${ }^{10}$ No estamos con esto afirmando que en los relatos no pueda aparecer primero la resolución y luego la complicación; en los cuentos que venimos analizando pudo haberse dado algo como Había una vez una familia de pájaros. La mamá sacó a uno del nido porque se enfermó. Lo que se quiere hacer notar es que los niños de la muestra prefirieron contar los eventos en el orden en que ocurrieron en la "vida real". Esto no ocurrió en todos los textos expositivos, pero “(...) when tense does not tell about the sequence of events, the principle of iconicity resolves the problem" (Nara, 2001: 38).

${ }^{11}$ En adelante distinguiremos las muestras, así: NC quiere decir narración de Cartagena; NB, narración de Bogotá; EC, texto expositivo de Cartagena; EB, texto expositivo de Bogotá.
} 
[2] no tuvo más remedio q' sacarlo de su nido porq' estaba muerto y le prendia su enfermedad a los demás [NB]

[3] con mucho dolor lo tuvo que sacar del nido [NC]

[4] apenada por la muerte de su polluelo tubo que lansarlo del nido después de eso tuvo que tener mucho cuidado con eso [NC]

[5] ya estaba muerto su madre lo tiene saca osino muy pronto no habra ni uno [NB]

[6] como en todo nido cuando un pajaro se muere la mama lo tiene que sacar del nido y asi fue

[7] la mama lo tuvo que sacar al pajaro a la calle y callo muy muerto [NB]

[8] cuando llego la hora de su muerte murio y le tuvieron que sacar del nido [NB]

Como se puede prever, estas formas aparecieron preferentemente en la categoría resolución de los textos narrativos: dada una situación desequilibrante -un pajarillo se ha enfermado o muerto en el nidono parece posible sostenerla debido, posiblemente, a los múltiples problemas inusuales acarreados o el caos constante en la vida. En este caso, por ejemplo, mantener el pichón muerto en el nido puede producir problemas que afecten la salud de los otros. Es por esto que después ("pasaron días y días"), y al notar la presencia de nuevos problemas ("se estaban contagiando"), los padres, en especial la madre, tienen que sacar el pichón del nido.

Ahora bien, como se observa, algunas de las construcciones numeradas de [1] a [8] tienen la forma del auxiliar en pretérito indefinido y el auxiliado en infinitivo. Según Gómez Torrego, en estos casos el valor de la perífrasis es de obligación pasiva o de necesidad. Algunos de los niños plantean explícitamente el porqué de esa necesidad, aún a pesar del dolor que esa decisión pueda causar, como lo señalan [2], [3] y [4]. En contraste, ninguno de los tres textos expositivos que introduce esta perífrasis modal menciona el dolor:

[9] cuando el ave tiene sus crías y una se enferma (...) sus padres tiene que sacarla del nido pues si la dejan tendrán esa enfermedad. [EB] [10] su mamá tuvo que expulsarlo (...) porque podía infectar a sus demás pichones [EB] [11] tiene que expulsarlo del nido porque puede contagiar a los demás [EC] 
Veamos la siguiente perífrasis:

[12 no hubo mas remedio q' desechar ${ }^{12}$ su hijo para q' los otros pequeños no se fueran a enfermarse [NB]

A pesar de que la perífrasis aquí encontrada no pertenece a la clase "tener que + infinitivo", sino a "haber que + infinitivo", sí tiene en común con [2] el criterio de necesidad/obligación. Así lo señala Gómez Borrego (1999), refiriéndose a las perífrasis de "haber que + infinitivo". "Con el auxiliar en pretérito indefinido y futuro imperfecto de indicativo unido al infinitivo siempre se suele añadir al significado de necesidad un matiz de resignación por parte del hablante" (3358). Ese efecto de resignación es explícito en los casos encontrados en [2] y [12]: ambos niños introducen la forma no "haber/tener más remedio que". La perífrasis "tener que + infinitivo", entonces, resultó adecuada para que los niños establecieran un fuerte contraste entre los textos narrativos y expositivos. En los primeros es propicio introducir actitudes afectivas; en los segundos, epistémicas.

\section{Ir a + infinitivo: ¿desaparición del futuro simple?}

En las perífrasis de este tipo predomina el valor de temporalidad futura, como en los siguientes casos:

[13] querían salvarlo porque si no lo iban a botar [NB]

[14] cuando iba a nacer... [NB]

[15] para que los otros no se fueran a enfermar [NB]

[16] se iba ir al cielo (...) se iba a encontrar con su mamá [NC]

[17] estaba muy feliz porque (...) ya iba tener hijos [NC]

[18] le decía (...) mamá creo que me voy a morir [NC]

Respecto a las formas con "iba a + infinitivo", dice Gómez Torrego (1999): "El valor de futuridad también aparece con el auxiliar en pretérito imperfecto de indicativo. En este caso, la sustitución es posible con el condicional simple" (3368). Nótese que la equivalencia mencionada sería apropiada para los casos [13], [16] y [17], pero menos en [14], porque en este último se añade un rasgo aspectual incoativo: “[...] la perífrasis y el futuro no son variantes libres, pues [en algunas ocasiones] el uso del futuro simple [y del pospretérito o condicional] no

\footnotetext{
${ }^{12}$ Una interesante diferencia que no comentaremos aquí encontrada en los textos escritos por los niños tiene que ver con las aloformas usadas para mencionar el hecho de sacar el pajarillo del nido. Tanto en Cartagena como en Bogotá se acudió a los verbos sacar, arrojar, echar. Pero hubo otro tipo de verbos no usados en Cartagena: botar y desechar y otros no usados en Bogotá: tirar y lanzar.
} 
posee el valor aspectual incoativo de 'estar a punto de'"(Gómez Torrego, 1988: 68). En el caso [14], entonces, parece obligado el copretérito: “...cuando iba a nacer [nacería ( $i$ ?] su última cría...”.

Para algunos autores el uso de formas con "ir/iba a + infinitivo" es índice de la preferencia que muestran algunos hablantes por reemplazar con ellas el futuro simple y el pospretérito, respectivamente, tanto así que proponen que estas formas se incluyan en el paradigma verbal como ya lo hicieron los tiempos compuestos, los cuales son perífrasis verbales. Al respecto, Nelson Cartagena señala:

Los tipos voy a hacer e iba a hacer [...] tienen un valor puramente temporal. El primero de ellos presenta una continua y acelerada extensión de su uso temporal puro, en detrimento del empleo del futuro simple, desde el Siglo de Oro hasta la actualidad [...] lo que a nuestro juicio legitima considerar estas dos formas como tiempos compuestos integrados a los paradigmas del verbo español (Cartagena, 1999: 2965).

Cabe resaltar que en los textos narrativos sólo un niño usó el pospretérito ("contagiaría") y otro la perífrasis en presente: ("me voy a morir"). Éste último lo hace porque introduce un diálogo en estilo directo. Sin embargo, en los textos expositivos de niños bogotanos aparecieron cinco casos de uso de pospretérito y ninguno en niños cartageneros. Es decir, respecto a lo que se señaló más arriba acerca de la forma "iba a ir + infinitivo", los niños bogotanos prefirieron el uso alternativo del pospretérito.

Las perífrasis del tipo "ir a + infinitivo" encontradas en los textos expositivos son las siguientes:

[19] les voy a explicar [EB]

[20] muy pronto va a morir [EB]

[21] ya no va a tener a quien alimentar (...) se va a sentir muy triste $[\mathrm{EC}]$

[22] si ve uno que se va a morir lo saca del nido [EC]

Todas ellas aparecen en presente, como es lo esperado en los textos expositivos, pero con el valor temporal de futuro. Lo interesante aquí es que los niños prefirieron, la perífrasis al futuro simple. De este último aparecen sólo dos casos: "tendrá [EB]" y "morirán [EC]". La alternancia "ir a + infinitivo/futuro simple" puede darse en [19], [20] y [21], pero no en [22]. Las primeras construcciones tienen un valor temporal de inmediatez y el hecho de escoger el futuro simple o la forma perifrástica puede estar asociado a la expresión de una realidad 
física, o como lo explica Gómez Torrego, puede referirse a una realidad psicológica deseada, temida o vista como más segura. Así, los hechos enunciados con la perífrasis se ven más próximos y seguros que los dichos en futuro simple. Como se señaló, ello no ocurre con la forma [22]. En este caso, la introducción de una oración condicional plantea el hecho como posible, restándole valor de generalidad.

\section{Perífrasis de gerundio: ¿está desapareciendo en Bogotá?}

El carácter imperfectivo, de acción durativa, propio de las perífrasis de gerundio, constituye un rasgo común en las perífrasis de este tipo producidas por los niños. En algunas se añade un cierto efecto de prolongación de la acción, como se aprecia en los siguientes ejemplos. Todos ellos correspondientes a textos narrativos:

[23] voló hasta un palo allí se recostó en él y se estaba muriendo [NC]

[24] pasaron días y días y se estaban contagiando [NC]

[25] él se la pasó todo el día enfermo y sus hermanos [se la pasaron] jugando [NB]

[26] poco a poco el pollito fue callando, callando hasta que murió [NB]

[27] el pichoncito se puso más y más mal parecía que se estuviese muriendo [NC]

[28] No digas eso que yo te quiero mucho para que estés diciendo eso $[\mathrm{NC}]$

Gómez Torrego explica los valores estilísticos de perífrasis como las anteriores así: "[Los] efectos estilísticos, casi cinematográficos, quedan aún más destacados cuando se pasa del plano narrativo al descriptivo [...] cabe la sustitución de la forma perifrástica por el tiempo simple correspondiente; pero está claro que los efectos estilísticos descriptivos quedarían más borrosos" (1988: 140).

Además de ser preferible la forma en gerundio para provocar esos efectos, éstos se hacen más marcados si se acompañan de recursos como la repetición del gerundio (como en [26]), o de las locuciones adverbiales [24], [27]. Estos recursos estilísticos no fueron usados en las perífrasis de gerundio de los textos expositivos. Allí tuvieron, más bien, una función deíctica por cuanto se usaron para describir los cuadros que se les presentó. Además, tal como lo expresa Aoto (2003), "ESTAR + ger., en el español de América, alcanza a reemplazar el presente simple" (22). Esto puede verse en los siguientes ejemplos (reemplácese las construcciones en gerundio por presente simple): 
[29] bueno, hoy les voy a explicar el planteamiento que aquí aparece (...) en la primera podemos observar al ave alimentando su cría (...) luego el ave está expulsando al pichón de su nido (...) en la última que el pichón está muerto [EB]

[30] como se dan cuenta en el primer cuadro la madre está alimentando a sus crías, como se dan cuenta en el segundo cuadro.. [EC]

[31] bueno, primero el ave está alimentando a sus crías, después. [EC]

[32] aquí está pasando que un pichoncito (...) los demás pichoncitos están alimentándose... [EC]

Una interesante diferencia entre los textos de los niños cartageneros y bogotanos lo constituyó el uso de la forma "estar + gerundio". Se usaron doce formas perifrásticas en gerundio; ocho de ellas corresponden a "estar + gerundio". Lo interesante es que son los niños cartageneros quienes preferentemente las usan: cuatro niños en los textos narrativos y tres en los expositivos. En contraste, ningún niño bogotano la usó en los textos narrativos y sólo uno lo hizo en los expositivos. Dada la virtual no presencia de "estar + gerundio" en las narraciones de Bogotá, tal vez sea de interés señalar (para contrastar con investigaciones futuras) que, según Eugenia Sebastián (1991), el progresivo es una forma que tiende a desaparecer, al menos en las narraciones orales, a partir de los cinco años de edad, hecho que, según cita en su artículo, también fue observado en un trabajo realizado con adultos por Silva-Corvalán (1983). Argumenta Sebastián que ello puede deberse a que en español el valor del progresivo no se pierde si se usan otras formas. Es decir, tiene un alto grado de opcionalidad: "Así, por ejemplo, en español podemos contestar utilizando una forma progresiva a una pregunta formulada con una forma no progresiva, aunque no es obligatorio, como en ¿Qué haces? Estoy comiendo/ Como. 0 a la inversa." (1991: 187).

Debe aclararse que los hallazgos de Sebastián y de Silva-Colvarán respecto a este tema se basan en narraciones orales de hablantes de la Península Ibérica, y que, por otro lado, Gómez Torrego advierte que “[...] en algunos sitios de Hispanoamérica el empleo de estar + gerundio tiene usos más ampliados que en España, llegando, incluso, a suplantar en todos los terrenos a los tiempos de la conjugación verbal" (1988: 146). Por último, no sobra advertir que las perífrasis antes descritas ("tener que + infinitivo"; "ir a + infinitivo" y las de gerundio") no fueron las únicas usadas por los niños. Lo que se quiere destacar es que ellas contribuyen a la tipificación de los textos 
narrativos y expositivos. Queda por explicar con mayor profundidad de qué modo.

\section{Temporalidad de las perífrasis}

No es difícil advertir que las perífrasis antes reseñadas tienen una característica: las correspondientes a textos narrativos se expresan en pasado y las de los textos expositivos en presente, es decir, la distribución de patrones gramaticales se relaciona con la estructura del discurso:
[...] la gramática crea y refleja, de diversos modos, la organización de nivel superior de los textos [...] ciertas clases de patrones gramaticales pueden asociarse con determinados tipos de unidades de la estructura del tex- to: por ejemplo, los verbos en pretérito simple con las cláusulas narrativas [...] (Cumming y Ono, 2003: 185).

Subyace a esta apreciación una noción que considera que las oraciones en el discurso establecen relaciones a partir de las cuales pueden formularse reglas que determinan su combinación. Esas relaciones pueden ser de orden temporal y caracterizar tipos de textos. Smith (2003) identifica con el rasgo temporalidad los textos narrativos y con atemporalidad los informativos. Ese rasgo en los textos narrativos permite su progresión, determinando un orden narrativo en donde la ocurrencia de unos eventos incide en la de otros: "[...] narrative consists of events that occur in one after the other in time"(11). En contraste, el avance o progresión de los textos expositivos depende más del referente. Usualmente las oraciones en las narraciones describen una transición temporal de un estado de cosas a otro (Ochs, 2003). Esta transición se da mediante cláusulas ordenadas temporalmente: “[...] podemos definir una narrativa mínima como una secuencia de dos cláusulas que están ordenadas de acuerdo con el tiempo, es decir, de un cambio en el orden resultará un cambio en la secuencia temporal de la interpretación semántica general" (Labov, 1972: 11. Traducción de la Universidad del Valle).

En los textos expositivos "its discourse is determined by its subject, and the logical structure built in its exposition" (Yaari, 1998: 26). Es decir, en contraste con los narrativos, el orden temporal de los eventos no es característica necesaria para identificar los textos expositivos. 


\section{Conclusiones}

En este breve estudio se constató la presencia y los valores de las perífrasis verbales "tener que + infinitivo"; "ir a + infinitivo", y algunas de gerundio, en textos narrativos y expositivos escritos por niños cartageneros y bogotanos. En cuanto a la primera, los dos grupos de niños imprimieron en ambos tipos de textos un valor modal de necesidad que, como lo explica Sirbu-Dumitrescu (1988), es también de imposición: "el sujeto de la acción verbal no tiene opción [...]" (4). Algunos niños, sin embargo, diferenciaron los dos tipos de texto modalizando afectivamente el narrativo mediante el uso de términos que denotan dolor. Por su parte, a la perífrasis "ir a + infinitivo" le es dado en común el rasgo de temporalidad futura. No obstante, se encontraron algunas interesantes opciones regionales respecto a los usos alternativos de esta perífrasis con el pospretérito y el futuro simple: el pospretérito apareció en varios textos expositivos escritos por niños bogotanos y en ninguno de los cartageneros. Tanto los niños cartageneros como los bogotanos prefieren la perífrasis al futuro simple. En cuanto a las perífrasis de gerundio, fue notorio el valor estilístico (expresivo) impreso por ambos grupos de niños en las narraciones, y el de demarcar un futuro cercano, mientras que en los textos expositivos se usó, virtualmente, en reemplazo del presente simple. Por otro lado, se observó la ausencia de la forma "estar + gerundio" en Bogotá. Sin duda, estos hechos merecen ser estudiados de nuevo en otro grupo de datos ${ }^{13}$.

Por último, se observó que, como era de esperarse, los textos narrativos y expositivos escritos por los niños cartageneros y bogotanos ostentan el rasgo temporalidad/atemporalidad, respectivamente. El rasgo temporalidad permite el avance de la narrativa y que las situaciones se relacionen unas con otras. Por ello, el orden en que ellas ocurren es vital para su comprensión. En contraste, el texto informativo no está temporalmente organizado. Su interpretación, en cuanto a lo temporal, es deíctica (Smith 2003).

Finalmente, con este trabajo se pretende contribuir al estudio de los rasgos linguísticos que distinguen tipos de textos bajo la idea de

${ }^{13}$ Es oportuno señalar aquí algunas otras conclusiones del estudio que relaciona categorías textuales con formas verbales y temporalidad (Fonseca, 2007): (1) Los niños bogotanos exhiben en sus textos mayor diversidad verbal. Los cartageneros, en contraste, "respetan" más las formas temporales típicas de los textos: el pasado en los narrativos, el presente en los expositivos. (2) Los niños cartageneros usan mayor número de cláusulas verbales (¿responderá esto a la fama de 'dicharacheros' de los costeños?) ¿Pueden estos hechos ser índice de, por ejemplo, una mayor 'facilidad' para escribir de los niños cartageneros? 
que una adecuada evaluación de la producción textual puede incluir múltiples aspectos que relacionan características de los hablantes/ escritores (el sexo, la edad, la condición social) y características del texto (la modalidad oral o escrita, el género narrativo o expositivo) con las opciones que ofrezca la lengua o variedad lingüística usada. Al respecto, Berman y sus colaboradores (2002) señalan que los estudios contrastivos pueden incluir: 1) el análisis de pronombres; la construcción de la cláusula; el modo; la voz. 2) La explicación de la diversidad intratextual, es decir, la mezcla de diferentes orientaciones, actitudes y niveles de especificidad. Estos y otros elementos relacionados pueden estudiarse desde perspectivas que involucren los cambios de edad y de modalidad (oral vs. escrito). Nosotros lo hicimos desde una que, al parecer, en nuestro medio, aún no ha sido abordada: desde lo regional.

\section{Bibliografía}

Aoto, Seiichi (2003). “Comentarios sobre Varilex 10. Acerca de la variación de las perífrasis verbales de gerundio", en Varilex, Variación léxica del español en el mundo, $\mathrm{N}^{\circ} 11$.

Berman, R.; Ragnarsdóttir, H.; Stromqvist, S. (2002). "Discourse stance”, en Written Language and Literacy, Vol. 5, 22. Visitado entre el 20 y el 30 de octubre de 2007, recuperado de: learn.snunit.k12.il/snunit/lashon/upload/teachers

Bruner, J. (1991). Actos de significado. Más allá de la revolución cognitiva. Madrid: Alianza.

(1994). Realidad mental y mundos posibles: los actos de la imaginación que dan sentido a la experiencia. Barcelona: Gedisa.

Callaway, Ch. y Lester, J (2001). "Narrative prose generation". Visitado entre el 20 y el 30 de octubre de 2007, disponible en http://research. csc.ncsu.edu

Cartagena, Nelson (1999). "Los tiempos compuestos", en Bosque I. y Demonte V. (eds.). Gramática descriptiva de la lengua española. Vol. 2. Madrid: Espasa Calpe.

Cumming, S y Ono, T. (2003). "El discurso y la gramática”, en Teun van Dijk (comp.) El discurso como estructura y proceso. Estudios sobre el discurso I. Una introducción multidisciplinaria. Barcelona: Gedisa.

Fogsgaard, L. (2002). "Algunas perífrasis aspectuales del español". Universidad de Alicante. Visitado entre el 20 y el 30 de octubre de 2007, recuperado de publicaciones.ua.es/filespubli/ pdf/02127636RD1973134.pdf

Fonseca, Clara (2007). "Formas verbales y temporalidad en conexión con la estructura de textos narrativos y expositivos escritos por niños cartageneros y bogotanos. Cartagena". Manuscrito no publicado. 
Gómez Torrego, L. (1999). “Los verbos auxiliares. Las perífrasis verbales de infinitivo", en Bosque I. y Demonte V. (eds.). Gramática descriptiva de la lengua española. Vol. 2. Madrid: Espasa Calpe. (1988). Perífrasis verbales. Sintaxis, semántica y estilística. Madrid: Arcos Libros S.A.

Labov, William. (1972). Language in the inner city. Philadelphia: University of Pennsylvania Pres. . (1988). La transformación de la experiencia en sintaxis narrativa. Cali: Universidad del Valle. Centro de traducciones. Traducción de Martha de Cobo.

(2006). "Narrative pre-construction", en Narrative Inquiry, 16:1. Recuperado de www.ling.upenn.edu/wlabov/Papers

Marín, Rafael (2000). “El componente aspectual de la predicación”. Universidad Autónoma de Barcelona. Recuperado de www.tdcat.cbuc. es/TDX-0726101-094043/index

Nara, H. (2001). "Tense alternation in written narrative texts in Japanese. A case study of Natsume Sooseki's Botchan". Visitado entre el 20 y el 30 de octubre de 2007, recuperado de aall.ufl.edu

Olbertz, H. (2001). "El orden de los constituyentes en la combinación de perífrasis en español”, en Revista española de lingüística, 31, 2, pp. 431-453. Recuperado de http://www.uned.es

Ragnarsdóttir Hrafnhildur, Aparici Melina, Cahana-Amitay Dalia, van Hell Janet and Viguié Anne (2002). "Verbal structure and content in written discourse: expository and narrative texts", en Written Language and Literacy, 5:1, 95-125.

Reboul, Oliver (1981). Lenguaje e ideología. México: F.C.E.

Sebastián, E. (1991). "El desarrollo del sistema de referencia temporal en español: un paseo por la morfología verbal”, en Anales de psicología (2), 181-196. Recuperado de www.um.es/analesps

Sirbu-Dumitrescu, Domnita. (1988). “Contribución al estudio de la semántica de los verbos modales en español (con ejemplos del habla de Madrid)", en Hispania, vol. 71, $\mathrm{N}^{\circ} 1$.

Smith, C. (2003). "Aspectual entities and tense in discourse", en P Kempchinsky and S. Roumyana (eds). The Syntax, Semantics and Acquisition of Aspect. Kluwer. www.uiowa.edu/ linguist/workshop/ pdf/Smith.pdf

Van Dijk, Teun (1983). La ciencia del texto. Madrid: Paidós.

Yaari, Y. (1988). “Texplore-exploring expository texts via hierarchical representation". Visitado entre el 20 y el 30 de octubre de 2007, recuperado de http://acl.upenn.edu 
